\title{
Dissolution of Organic Components of Straw by Ionic Liquid
}

\author{
Hua Chen, ${ }^{\mathrm{a}, \mathrm{b}}$ Junsheng Song, ${ }^{\mathrm{a}, *}$ Xufeng Qiu, ${ }^{\mathrm{c}}$ Qizhong Wo ${ }^{\mathrm{d}}$ Huabo Yao, \\ Bingbing Zheng, ${ }^{\mathrm{b}}$ Liuhao Jiang, ${ }^{\mathrm{a}}$ Jun Sun, ${ }^{\mathrm{b}}$ Hong Zhang, ${ }^{\mathrm{a}}$ Hui Pei, ${ }^{\mathrm{a}}$ and Jinmei Sun ${ }^{\mathrm{a}}$
}

\begin{abstract}
An ionic liquid was used in this work to dissolve rice straw at $90{ }^{\circ} \mathrm{C}$ to explore the dissolution of cellulose, lignin, and hemicellulose in the straw at different treatment times. Compared with traditional methods, the method involved short time and high efficiency. The residual amounts of multiple substances were evaluated at different time periods. The results showed that the dissolution rate of triglyceride fats, water-soluble pectin, and lignin reached their maxima at $10 \mathrm{~min}$, after which the dissolution rates decreased. Because lignin is wrapped as an outer layer surrounding cellulose and becomes dissolved in preference to hemicellulose and cellulose, cellulose and hemicellulose dissolve minimally at the beginning of the reaction, and the dissolution rate is slow. This study showed that there is a certain possibility for the direct utilization of ionic liquids for the treatment of straw biomass.
\end{abstract}

Keywords: Straw stalks; Ionic liquid; Residual volume

Contact information: a: Key Laboratory of Recycling and Eco-treatment of Waste Biomass of Zhejiang Province, Zhejiang University of Science and Technology, 310023, Hangzhou, China; b: Hangzhou Nanqi Technology Co., Ltd., 310023, Hangzhou, China; c: Zhejiang Hengchuan New Material Co., Ltd., 324400, Longyou, China; d: Zhejiang Paper Products Quality Test Center, 311400, Hangzhou, China; e: Bureau of Complaints and Proposals Administration, CPC Zhoushan Municipal Committee and Municipal Government, 316000, Hangzhou, China; *Corresponding author: 315269296@qq.com

\section{INTRODUCTION}

Cellulose is widely used in various fields because of its excellent properties (Hubbe and Lucia 2015). For example, Hubbe et al. (2014) reviewed the usage of cellulose-based adsorption materials to remove petrochemical pollutants from water. In addition, hemicellulose can be used to reduce water pollution (Ayoub et al. 2013). However, due to the difficulty of separating cellulose in plants, sometimes some cellulose-rich plants have been selected as organic fertilizers to achieve high value utilization (Hubbe et al. 2010). If cellulose can be separated better, it is expected that cellulose will be able to achieve higher value utilization, such as separation and preparation of nano-sized cellulose (Wang et al. 2020).

In recent years, ionic liquids have been widely used in the preparation and application of cellulose (Han et al. 2020). Man et al. (2011) used 1-butyl-3methylimidazolium hydrogen ionic liquid to treat microcrystalline cellulose to prepare cellulose nanocrystals. In addition, Kadokawa et al. (2008) used cellulose (15 wt\%) in 1butyl-3-methylimidazole ammonium chloride ionic liquid to quickly prepare a flexible gel material at room temperature. Deng et al. (2009) used ionic liquid to process and prepare nanoporous cellulose foam. Further, as ionic liquids are highly soluble green solvents, they impact the dissolution of hemicellulose and lignin. Sun et al. (2009) completely dissolved and partially delignified wood in 1-ethyl-3-methylimidazole acetate ionic liquid. In 
addition, Tan et al. (2009) used alkylbenzene sulfonate ionic liquid to extract lignin from cellulose at atmospheric pressure. Lee et al. (2009) used ionic liquids to selectively extract lignin from wood through mediation to promote the enzymatic hydrolysis of cellulose.

Since the emergence of ionic liquids, few studies have considered the dissolution of all chemical components of straw in ionic liquids with examination of the dissolution rate. Most scholars only separate the single components from rice straw to investigate methods to dissolve them in ionic liquids. For example, Pu et al. (2007) and others have studied the application of ionic liquids as aprotic green solvents of lignin, in which the lignin is separated from pine kraft pulp and used for dissolution experiments. With the further application of ionic liquids in various fields, the dissolution mechanisms of ionic liquids must be explored (Plechkova and Seddon 2008). This study used rice straw to investigate the dissolution of cellulose, hemicellulose, and lignin in straw in ionic liquids used to treat natural products. In addition, this study aimed to provide reference values for further research of ionic liquids.

\section{EXPERIMENTAL}

\section{Materials}

The straw used as the raw material was collected from a farm in Jining City in the Jiaxiang County of Shandong Province in China. The main raw material used in this experiment was untreated rice straw. The purchased straw was crushed using a Chinese medicine pulverizer (Yongkang Hongyang Electromechanical Co., Ltd., Yongkang, China) and then sieved. The straw powder of 40-mesh to 60-mesh in size was stored in a sealed container for over $24 \mathrm{~h}$ for further use and to achieve water balance. The ionic liquid used was produced by China Lanzhou Yulu Fine Chemical Co., Ltd. (Lanzhou, China). It consisted of 1-allyl-3-methylimidazolium chloride (Fig. 1), and its molecular formula is $\mathrm{C}_{7} \mathrm{H}_{11} \mathrm{~N}_{2} \mathrm{Cl}$.

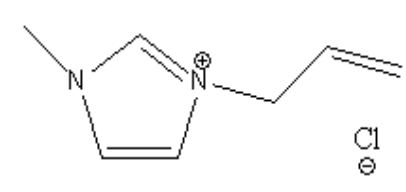

Fig. 1. Chemical structure of the ionic liquid used

\section{Methods of Measurement}

Traditional methods

Measurements were performed according to the TAPPI T204 cm-07 (2007), TAPPI T9 m-54 (1998), TAPPI T222 om-11 (2011), and TAPPI T211 om-07 (2007) methods for the measurement of organic solvent extracts, holocellulose, acid-incompatible lignin (AIL), and ash, respectively. The method employed was relatively independent for the determination of each component, and each determination was not affected by the determination of other components. However, the measurement methods employed could not measure the two components of hemicellulose and cellulose. The traditional analysis methods mainly include the quantitative analysis method of the chemical composition of Ramie, the Van Soest method, and the standard determination method of the chemical composition of papermaking raw materials. 
Common principle analysis of the three traditional wet chemical analysis methods indicates that sodium chlorite is often used to remove lignin under acidic conditions to obtain holocellulose, and a hot alkaline solution of $\mathrm{NaOH}$ is then used to extract hemicellulose. The hemicellulose and cellulose contents can be obtained based on the weight loss and the remaining residue weight. However, Buchala et al. (1972) found that removing lignin with sodium sulfite decomposed $8 \%$ of hemicellulose. Research by Carpita (1984) found that sodium chlorite has an effect on corn fiber polysaccharides, which causes increased error in test results. In addition, the traditional method has a long test time and complicated procedure.

\section{Experimental methods}

Due to the measure mental errors described and to achieve the aims of this experiment, the following experimental methods were used to measure the composition of the test samples. The experimental flow chart is shown in Fig. 2c. Table 1 indicates the yields of various components obtained after following the sequence in Fig. $2 \mathrm{c}$.

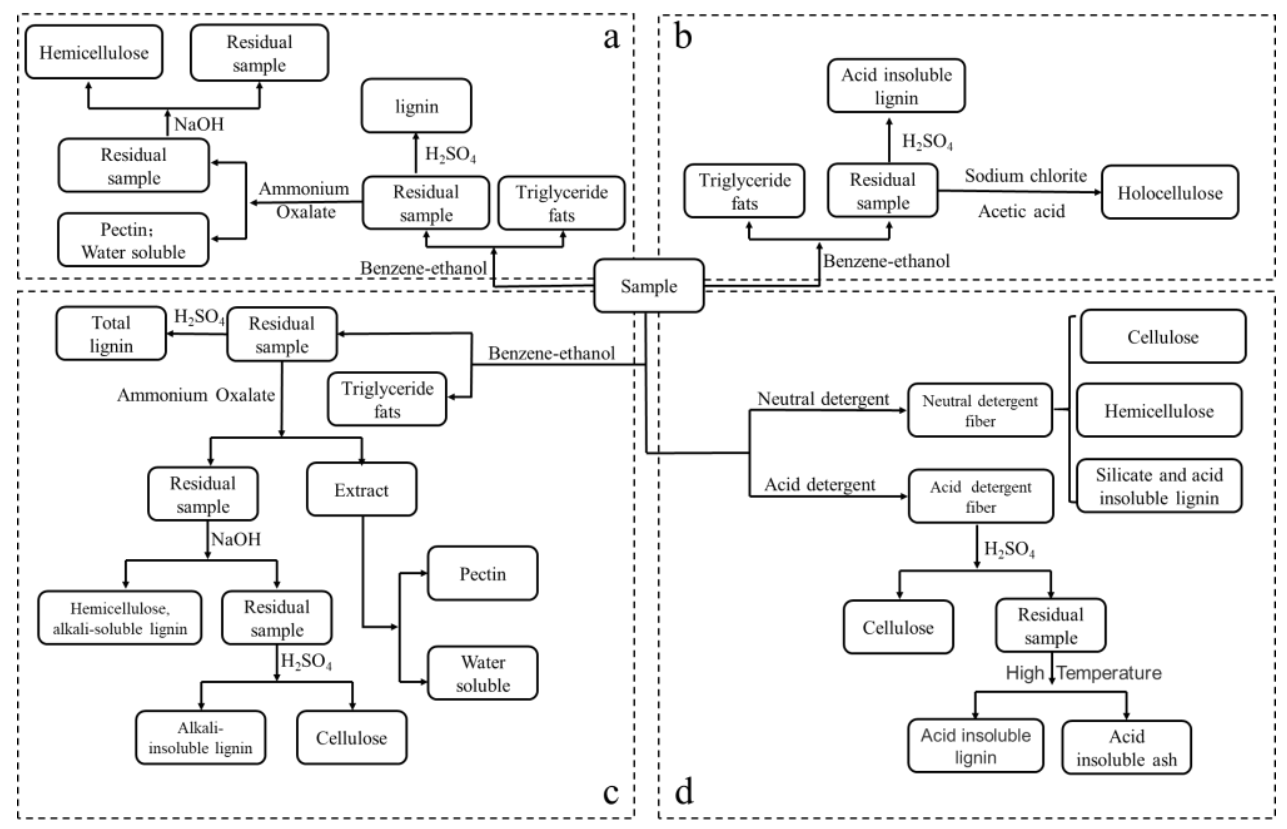

Fig. 2. a: Quantitative analysis of ramie chemical composition method flow chart; b: Van soest method flow chart; c: Experimental method flow chart; d: TAPPI method flow chart.

Table 1. Yields of Various Components

\begin{tabular}{|c|c|c|c|c|c|c|}
\hline $\begin{array}{c}\text { Time } \\
(\mathbf{m i n})\end{array}$ & $\begin{array}{c}\text { Triglyceride } \\
\text { fats }\end{array}$ & Lignin & $\begin{array}{c}\text { Pectin; Water } \\
\text { soluble } \\
\text { substance }\end{array}$ & $\begin{array}{c}\text { Hemicellulose, } \\
\text { alkali-soluble } \\
\text { lignin }\end{array}$ & $\begin{array}{c}\text { Alkali- } \\
\text { insoluble } \\
\text { lignin }\end{array}$ & Cellulose \\
\hline $\mathbf{0}$ & $9.39 \%$ & $23.6 \%$ & $12.05 \%$ & $45.1 \%$ & $2.61 \%$ & $42.8 \%$ \\
\hline $\mathbf{1 0}$ & $1.88 \%$ & $16.5 \%$ & $9.02 \%$ & $44.4 \%$ & $3.57 \%$ & $41.2 \%$ \\
\hline $\mathbf{2 5}$ & $1.20 \%$ & $18.4 \%$ & $7.81 \%$ & $42.8 \%$ & $3.26 \%$ & $43.0 \%$ \\
\hline $\mathbf{4 0}$ & $1.57 \%$ & $12.8 \%$ & $7.76 \%$ & $39.9 \%$ & $2.99 \%$ & $40.8 \%$ \\
\hline
\end{tabular}

The experimental process consisted of placing $2 \mathrm{~g}$ of the prepared sample into the fat extractor and pouring the extraction liquid (benzene ethanol mixed solution; volume 
ratio $2: 1$ ) into the flask. The extraction time was $5 \mathrm{~h}$ at constant temperature, and the reflux rate during extraction was 4 times/h to 6 times/h. The sample was then baked to a constant weight at $110{ }^{\circ} \mathrm{C}$, placed in a desiccator to air dry for $24 \mathrm{~h}$, and weighed after cooling. Then, the extracted triglyceride fats sample was placed into $300 \mathrm{~mL}$ of $5 \mathrm{~g} / \mathrm{L}$ ammonium oxalate solution for extraction. The extraction time was $6 \mathrm{~h}$, and the extraction temperature was $90{ }^{\circ} \mathrm{C}$. The weight loss was determined as the mass of pectin and water-soluble matter. Next, the sample extract was taken out, and the galacturonic acid content in the extract was detected by an ultraviolet spectrophotometer (UV-2600 UV-visible spectrophotometer, Shimadzu, Tokyo, Japan). The wavelength of the ultraviolet spectrophotometer was 530 $\mathrm{nm}$. The pectin content can be obtained by measuring the galacturonic acid content.

After the removal of impurities, which included triglyceride fats, water-soluble substances, and pectin, $1 \mathrm{~g}$ of the sample was placed into $30 \mathrm{~mL}$ of $72 \%$ sulfuric acid solution, placed at room temperature for $24 \mathrm{~h}$, diluted to $300 \mathrm{~mL}$, and boiled for $1 \mathrm{~h}$. The remaining material was regarded as lignin.

After removal of impurities, which included triglyceride fats, water-soluble substances, and pectin, $1 \mathrm{~g}$ of the sample was placed into $150 \mathrm{~mL}$ of $\mathrm{NaOH}$ solution with a concentration of $20 \mathrm{~g} / \mathrm{L}$ and boiled for $4 \mathrm{~h}$. The weight of loss was the hemicellulose and alkali-soluble lignin content. The remaining samples were washed and dried. The residual samples treated with hot alkali were treated in $30 \mathrm{~mL}$ of $72 \%$ sulfuric acid solution for 24 $\mathrm{h}$, diluted to $300 \mathrm{~mL}$, and boiled for $1 \mathrm{~h}$. The residue consisted of alkali-insoluble lignin, and the weight of loss was the cellulose content.

The ash content was measured according to the TAPPI T211 om-07 (2007) standard method.

\section{Scanning electron microscopy (SEM) analysis}

Morphologies of the different treated straw surfaces were examined with a scanning electron microscope (SEM SU1510, Hitachi, Tokyo, Japan) operating at an accelerating voltage of $15 \mathrm{kV}$. Before observation, the samples were coated with gold using a vacuum sputter-coater (MSP-2S/MSP-Mini; IXRF, Inc., Travis County, TX, USA).

\section{Fourier transform infrared spectroscopy (FT-IR) analysis}

The FT-IR spectra of straw residue treated by ionic liquid at $0 \mathrm{~min}, 10 \mathrm{~min}, 25 \mathrm{~min}$, and 40 min and the FT-IR spectra of straw dissolved substances and straw materials were investigated. Fourier transform infrared spectra were recorded on spectrophotometer (8400S; Shimadzu, Kyoto, Japan). The number of scans was 32, and the resolution was 4 $\mathrm{cm}^{-1}$. The spectra were obtained within the range of 500 to $4000 \mathrm{~cm}^{-1}$ in the transmittance mode.

\section{X-ray Diffraction (XRD) analysis}

This experiment analyzed the crystallization status and crystallinity of straw raw materials, straw residues, and microcrystalline cellulose through X-ray diffraction (Rigaku, Tokyo, Japan) analysis. The XRD test parameters were $\mathrm{Cu}$ target, a tube pressure/tube flow of $40 \mathrm{kV} / 20 \mathrm{~mA}$, a scanning speed of $4^{\circ} / \mathrm{min}$, a scanning step length of $0.04^{\circ}$, and $2 \theta=5^{\circ}$ to $45^{\circ}$. The crystallinity was calculated and analyzed using Jade software (Materials Data Inc., jade6.0, Livermore, CA, USA).

Dissolution mechanism of ionic liquid 
Ionic liquid is a new type of green solvent with good solubility for cellulose, lignin, and hemicellulose (Swatloski et al. 2002; Plechkova and Seddon 2008). The dissolution mechanism of ionic liquids occurs mainly through anions and cations blocking the hydrogen bonds between cellulose, lignin, and hemicellulose (Lu et al. 2014). The dissolution mechanism of cellulose is shown in Fig. 3.

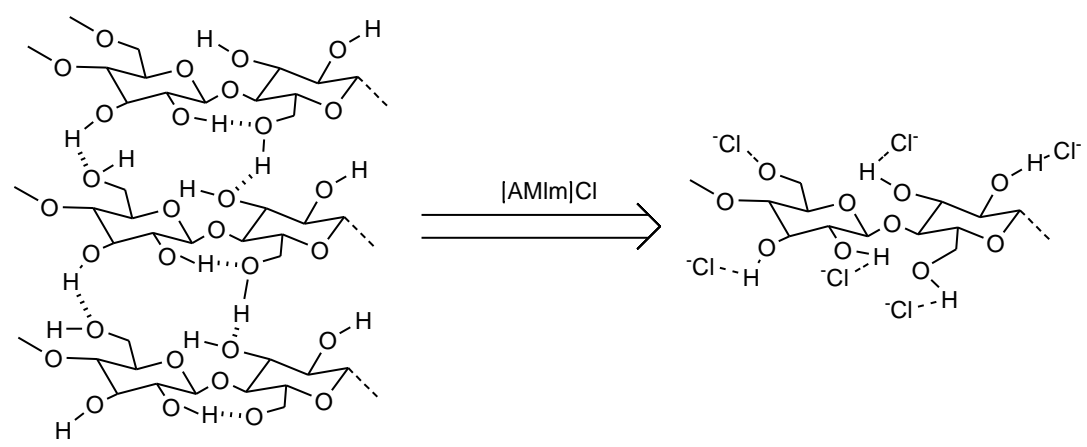

Fig. 3. The mechanism of ionic liquid dissolving cellulose (Remsing et al. 2006)

\section{RESULTS AND DISCUSSION}

\section{Effect of Temperature on Dissolution}

To better explore the dissolution of straw components in ionic liquid, the relationship between the solubility and the dissolution temperature was first determined. In this section, while maintaining a mass ratio of ionic liquid to rice straw of $7: 1$, the experiment explored the relationship between the solubility of straw in ionic liquid and the dissolution temperature to determine the optimal dissolution temperature of straw. The temperature was controlled by water bath heating. Figure 4 shows the effect of different temperature conditions on the dissolution rate of straw.

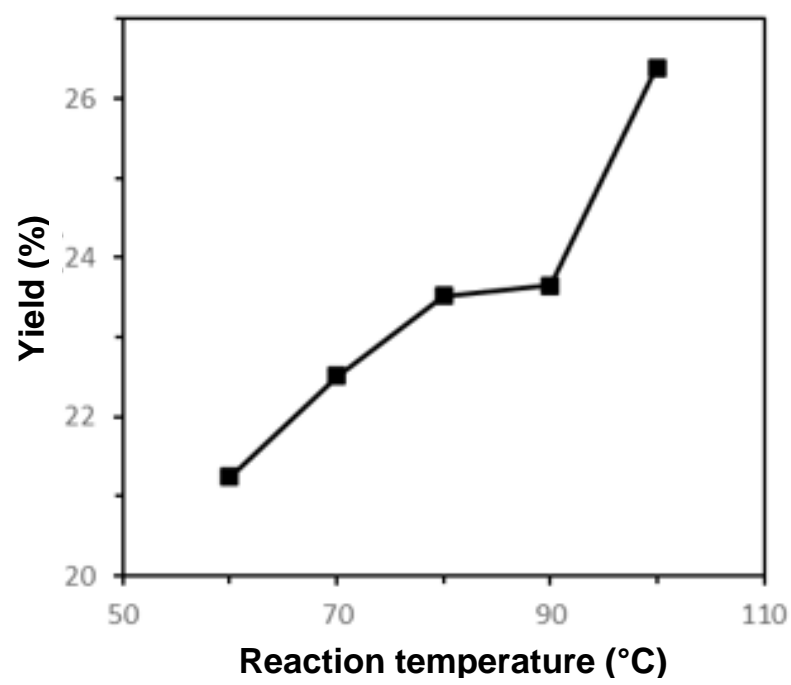

Fig. 4. Effect of temperature on dissolution rate. The dissolution rate is the ratio of dissolved amount to initial amount. 
Ionic liquids are a promising new class of solvents, some of which not only can dissolve cellulose, lignin, and hemicellulose, but also dissolve triglyceride fats, watersoluble matter, and pectin. Therefore, the yield of the dissolved substances was greater than the amount of dissolved cellulose due to the ionic liquid. The hydrogen bonds between the cellulose structures were destroyed, and the cellulose molecules and the organic components that were separated from the cellulose molecules were dissolved in the ionic liquid together (Pinkert et al. 2009). As the temperature rose, the yield continued to increase. However, the color of cellulose darkened at $100{ }^{\circ} \mathrm{C}$. These results indicated the possibility of fiber carbonization. Therefore, $90{ }^{\circ} \mathrm{C}$ was considered the most suitable temperature for dissolution.

\section{Straw Composition Changes with lonic Liquid Dissolution Time}

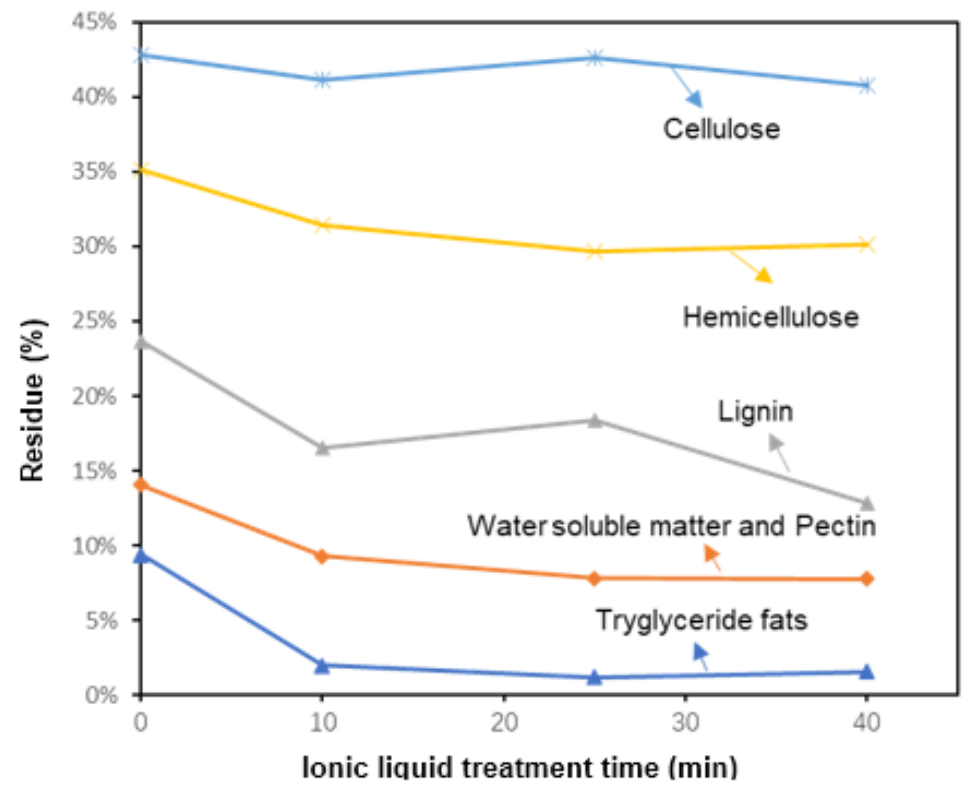

Fig. 5. The dissolution of triglyceride fats, water-soluble matter and pectin, lignin, cellulose, and hemicellulose in rice straw in ionic liquid over time

\section{Triglyceride fats}

In rice straw, the triglyceride fats are mainly composed of fatty acids, sterols, fatty alcohols, alkanes, $\beta$-diketones, and hydroxy- $\beta$-diketones (Athukorala and Mazza 2010). Figure 5 shows that the dissolution of triglyceride fats in the ionic liquid first decreased dramatically, decreased slowly, and then leveled off. At $10 \mathrm{~min}$, triglyceride fats were dissolved obviously. This showed that, as time increased, the dissolution rate of the triglyceride fats on the straw in the ionic liquid decreased slowly. According to the dissolution mechanism of the ionic liquid, the anions and cations in the ionic liquid directly acted on the triglyceride fats and broke bonds that held together mainly by van der Waals forces therein, thereby dissolving the triglyceride fats (Hubbe 2020). With regard to the dissolution of polysaccharides by ionic liquids, Remsing et al. (2006) used a carbon tracer to confirm its occurrence when they studied the dissolution of cellulose by ionic liquids. 


\section{Pectin and water-soluble matter}

As the measurement method used ammonium oxalate to remove pectin and watersoluble matter, and a large amount of aqueous solution was used during washing, it was difficult to measure the amount of galacturonic acid. Therefore, for the water-soluble matter and pectin in the straw, the experiment analyzed them as a whole. The results in Fig. 5 were consistent with the dissolution of triglyceride fats. Pectin and the water-soluble substances are essentially organic substances with triglyceride fats components, and both can be dissolved by ionic liquid (Athukorala and Mazza 2010).

\section{Cellulose and hemicellulose}

For cellulose, the dissolution trend was initially downward, and it later trended upward. In many studies, ionic liquids have been shown to have better solubility for cellulose (Pinkert et al. 2009; Makela et al. 2018; Chen et al. 2020a). Further, studies have shown that the relationship between the dissolution of cellulose and the time of ionic liquids meet the first-order reaction kinetics (Hazarika et al. 2012). The formula of firstorder reaction kinetics is shown in Eq. 1,

$$
-k_{\mathrm{d}} \times C_{\mathrm{x}}=\frac{\mathrm{d} C_{\mathrm{x}}}{d \mathrm{t}}
$$

where $k_{\mathrm{d}}$ is the reaction rate constant corresponding to the different components, which means that $d$ represents the different ingredients' name, $C_{\mathrm{x}}$ is the residual amount of cellulose in the straw at any time. When the value of time $t$ is $0, C_{\mathrm{x}}=C$, the residual amount of cellulose is equal to the initial amount. Further simplification is shown in Eq. 2,

$$
k_{d} \times t=\ln \left(\frac{C}{C_{t}}\right)
$$

where $C_{\mathrm{x}}$ is the residual amount corresponding to each component at time $t$.

In this experiment, the residual amount of cellulose initially decreased and then increased. When the data was forced to fit the first-order reaction kinetics curve, the value of $\mathrm{R}^{2}$, which was calculated by Origin software (Origin Lab Inc., Origin Pro 2017C, Northampton, MA, USA), was 0.7123 . The relatively low value of $\mathrm{R}^{2}$ implies that the dissolution process did not follow first-order reaction kinetics. Rather, it appears that the process is governed by complex reaction kinetics, which involved the dissolution reaction of multiple components rather than single reaction kinetics. In natural plants, the distribution, content, and density of cellulose, hemicellulose, and lignin are not uniform, so their dissolution sequence in ionic liquids is also different. The dissolution of a single fiber conforms to the first-order reaction kinetics (Makela et al. 2018), which requires high uniformity of cellulose. When Chen et al. (2020b) studied dissolving different fibers in ionic liquids, the fiber materials used were also uniform in density. This is the difference between the present research in contrast to that other studies described. This article aims to study the dissolution trend of each component in an unevenly mixed system. However, the difference may also be due to the dissolution time of the ionic liquid is not long enough.

The dissolution tendency of hemicellulose was faster than that of cellulose. This may have been because hemicellulose and lignin act as binders and fillers in grasses and are wrapped around the cellulose. Therefore, the ionic liquid may have preferentially opened the hemicellulose and lignin. Singh et al. (2009) studied alfalfa in ionic liquid and found that the secondary cell wall that contains a large amount of hemicellulose and lignin disappeared, which was consistent with the results of this experiment. 


\section{Lignin}

The trend for lignin was approximately the same as those of pectin and watersoluble substances. In ionic liquids, lignin can be dissolved in the same way. Different ionic liquids can dissolve lignin and cellulose to different degrees. In the combined system, the ionic liquid dissolved lignin more preferentially. The dissolution curve of this experiment showed that the residual amount of lignin decreased, and the residual amount of cellulose decreased slightly. This may have been because the ionic liquid preferentially broke the hydrogen bonds between lignin entities when dissolving the cellulose and lignin system, and a large amount of cellulose remained in the residue. When Miyafuji et al. (2009) observed the relationship between the yield of insoluble residues and temperature, they studied the dissolution behavior of wood in ionic liquid ([EMIm][Cl]) and found that the residue was mainly cellulose, which was consistent with the results observed in this experiment.

\section{FT-IR Spectra}

\section{FT-IR spectra of straw residue}

The infrared spectrum analysis of rice straw treated with ionic liquid is shown in Fig. 6. Over time, the infrared spectrum had almost no change, which indicated that the structure of the cellulose in the residue was not damaged. This finding was supported by the above-mentioned change in the cellulose content. The peaks located at $1118 \mathrm{~cm}^{-1}$ to $1123 \mathrm{~cm}^{-1}, 873 \mathrm{~cm}^{-1}$ to $880 \mathrm{~cm}^{-1}$, and $823 \mathrm{~cm}^{-1}$ to $832 \mathrm{~cm}^{-1}$ are related to lignin (Xiao et al. 2001). As the dissolution time increased, the peak shape began to broaden, which indicated that the lignin content was decreasing. In addition, bands related to the vibration of the aromatic ring of lignin (Sun et al. 2005) were observed at $1513 \mathrm{~cm}^{-1}$ and $1433 \mathrm{~cm}^{-1}$, and the changes were consistent with the above analysis. The peak at $1642 \mathrm{~cm}^{-1}$ represents hemicellulose. The intensity of this part of the peak did not change, which indicated that the dissolution of hemicellulose was incomplete. The same conclusion can be drawn from the peak at $1238 \mathrm{~cm}^{-1}$ (Alemdar and Sain 2008).

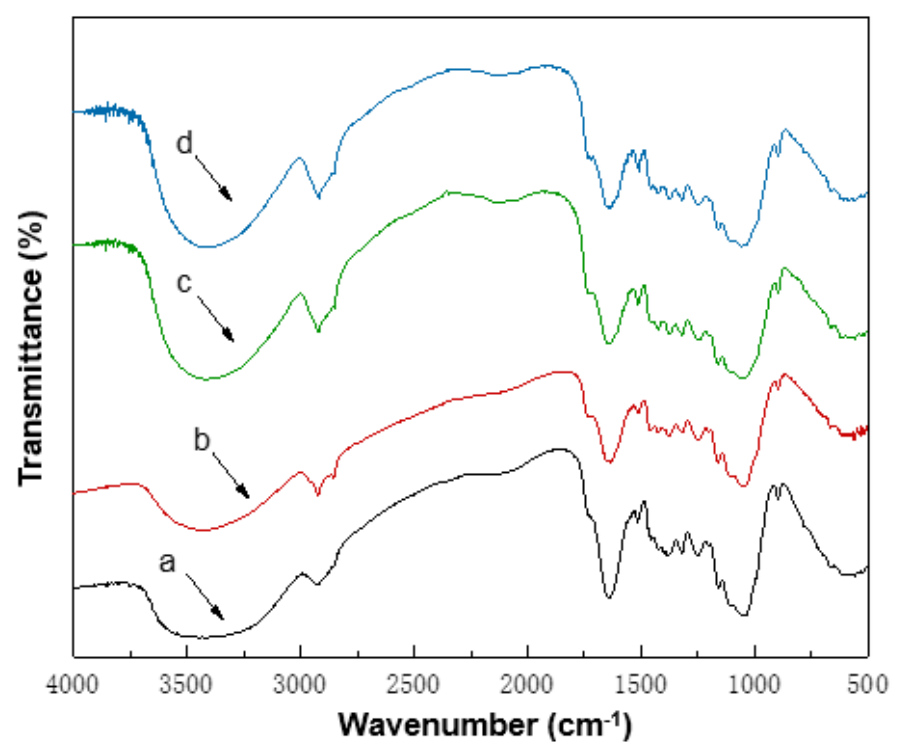

Fig. 6. The FT-IR spectra of straw residue treated by ionic liquid at 0 min (a), $10 \mathrm{~min}(\mathrm{~b}), 25 \mathrm{~min}$ (c), and $40 \mathrm{~min}(\mathrm{~d})$ 


\section{FT-IR spectra of straw dissolved substances}

The infrared spectrum analysis of the sample separated from the rice straw is shown in Fig. 7. These results make it possible to judge which chemical groups and substances tend to be dissolved tend to be dissolved. All the spectra showed the absorption peak of $\mathrm{C}-\mathrm{H}$ and aromatic ring vibration at $1457 \mathrm{~cm}^{-1}$ (Faix 1991). In the wavelength range of 1326 $\mathrm{cm}^{-1}$ to $1328 \mathrm{~cm}^{-1}$ there were obvious absorption peaks of lignin structural units, which included syringyl structural units and condensed guaiacol-based units. Respiratory vibration and $\mathrm{C}=\mathrm{O}$ stretching vibration of the aromatic ring of the guaiacol-based structural unit were observed in the range 1262 to $1266 \mathrm{~cm}^{-1}$. Strong absorption peaks caused by stretching vibrations of $\mathrm{C}-\mathrm{C}, \mathrm{C}-\mathrm{O}$, and $\mathrm{C}=\mathrm{O}$ appeared in the wavelength range of 1218 to $1224 \mathrm{~cm}^{-1}$. The absorption peak of $\mathrm{C}-\mathrm{H}$ parallel vibration on the aromatic ring appeared at $1024 \mathrm{~cm}^{-1}$. The absorption peaks at $1118 \mathrm{~cm}^{-1}$ to $1123 \mathrm{~cm}^{-1}, 873 \mathrm{~cm}^{-1}$ to $880 \mathrm{~cm}^{-1}$, and 823 $\mathrm{cm}^{-1}$ to $832 \mathrm{~cm}^{-1}$ indicated that all straw samples contained GSH structural units (Xiao et al. 2001). The absorption peaks of the $\mathrm{C}=\mathrm{O}$ stretching vibration of non-conjugated ketones, carboxyl groups, ester bonds, and acetyl groups appeared at $1718 \mathrm{~cm}^{-1}$ (Faix 1991). However, the absorption peak at this position was not detected in the infrared spectra of other dissolved samples, which indicated that the $\mathrm{C}=\mathrm{O}$ bond of the non-conjugated group of lignin was broken during the ionic liquid treatment.

The prominent band at $1042 \mathrm{~cm}^{-1}$ was due to the $\mathrm{C}-\mathrm{O}$ stretching, C-C stretching, or $\mathrm{C}-\mathrm{OH}$ bending of hemicellulose (Xiao et al. 2001). A weaker peak appeared at $461 \mathrm{~cm}^{-1}$, and there were many factors related to it. This result may have been due to the bending vibration of the methylene group $\left(\mathrm{CH}_{2}\right)$ in xylose or the asymmetric vibration of the methyl group $\left(\mathrm{CH}_{3}\right)$ in the lignin unit. At $900 \mathrm{~cm}^{-1}$, the absorption peak of cellulose was stronger than that of the original microcrystalline fiber, which indicated that the ionic liquid solution increased the non-crystalline area of the regenerated fiber and reduced the crystalline area after it was dissolved, which was also reflected in the XRD characterization.

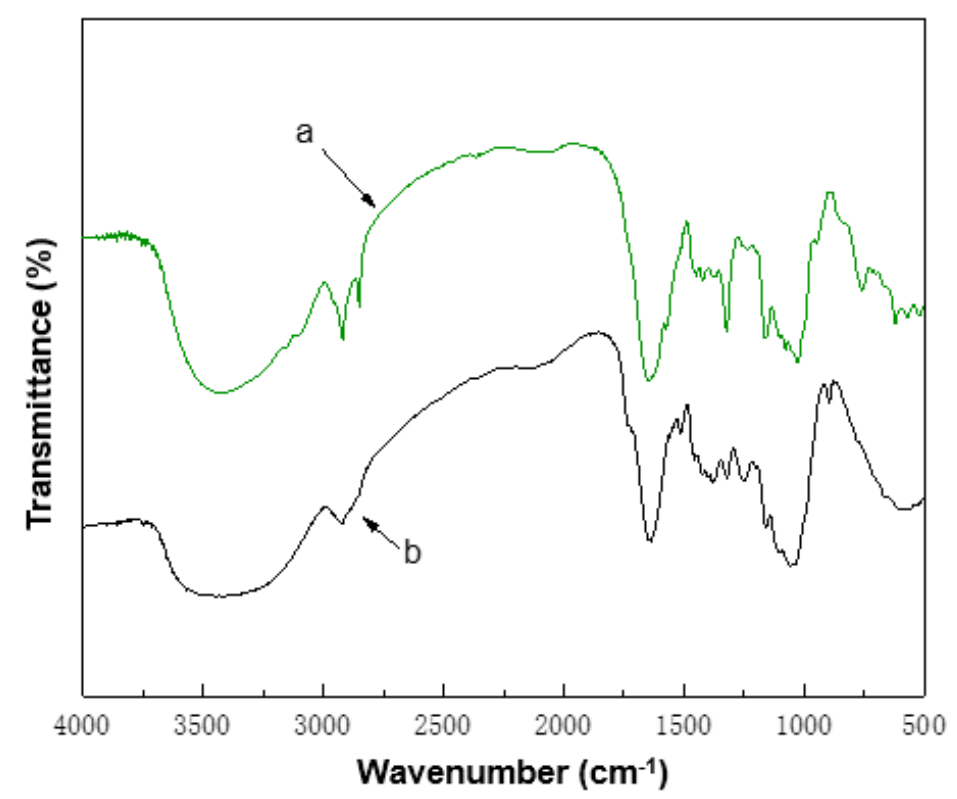

Fig. 7. The FT-IR spectra of straw dissolved substances which were precipitated after being dissolved by ionic liquid (a) and straw materials which were straw by physical crushing (b) 


\section{XRD characterization}

This experiment analyzed the crystallization status and crystallinity of straw raw materials, straw residues, and microcrystalline cellulose through XRD analysis. The XRD test parameters were $\mathrm{Cu}$ target, a tube pressure/tube flow of $40 \mathrm{kV} / 20 \mathrm{~mA}$, a scanning speed of $4 \% \mathrm{~min}$, a scanning step length of $0.04^{\circ}$, and $2 \theta=5^{\circ}$ to $45^{\circ}$. The images of straw raw materials, straw residues, and straw microcrystalline are shown in Fig. 8.

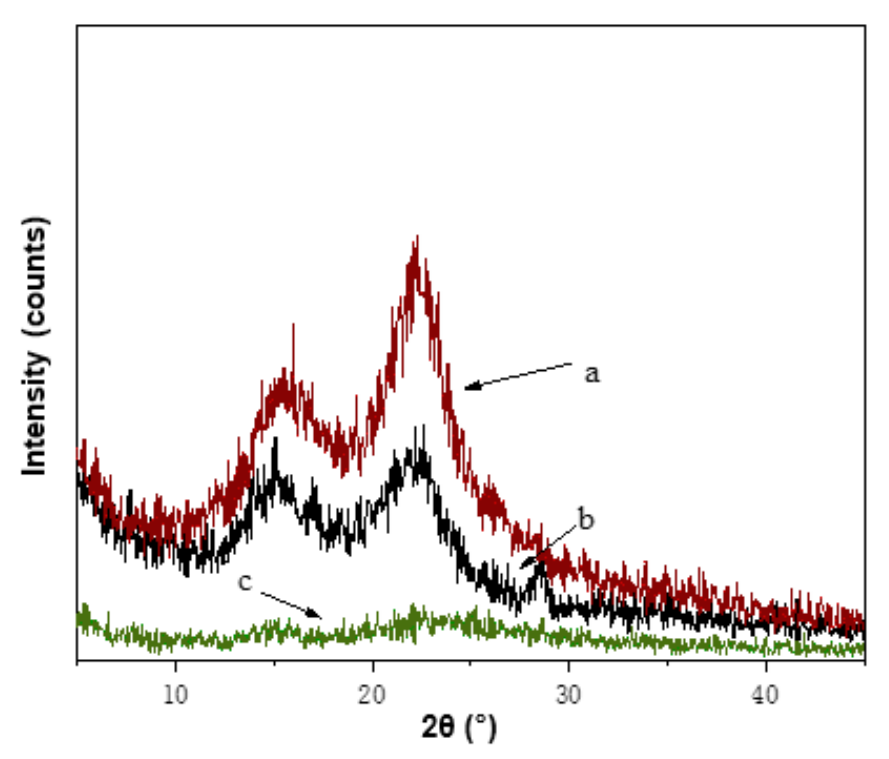

Fig. 8. The XRD of straw raw materials, which were straw by physical crushing (b), straw residues is the residues which were being treated by ionic liquid (a), and straw dissolved substances which were precipitated after being dissolved by ionic liquid (c)

Figure 8 shows that the crystal form of straw raw materials, straw residues, and straw microcrystalline did not change. There were crystallization peaks at $15.440^{\circ}$, $15.480^{\circ}$, and $22.714^{\circ}$ for straw raw materials and at $15.456^{\circ}, 16.920^{\circ}$, and $22.357^{\circ}$ for straw residues. In addition, there were crystallization peaks at $15.800^{\circ}, 16.640^{\circ}$, and $22.720^{\circ}$ for straw microcrystalline cellulose, which corresponded to the 101,101 , and 002 crystal planes of cellulose, respectively. These peaks are characteristic of cellulose. Thus, regardless of the raw material, the residue and product belonged to cellulose type I. The diffraction intensity of straw treated with ionic liquid was obviously enhanced, which indicated that the crystalline area increased, and the amorphous area decreased after the straw was treated with ionic liquid. The prepared microcrystalline cellulose had an amorphous microcrystalline cellulose film, so the diffraction intensity was not high. According to calculations and analysis, the crystallinity of straw raw material was $68.15^{\circ}$, the crystallinity of straw residue was $76.43^{\circ}$, and the crystallinity of straw microcrystalline cellulose was $49.43^{\circ}$. Ionic liquid treatment can increase the crystallinity of straw. This also verified the situation of the above test that is lignin dissolves preferentially over cellulose. Therefore, the cellulose in the crystalline area remained in the residue, while the lignin in the non-crystalline area dissolved, resulting in an increase in the crystallinity of the residue, which is consistent with the experimental results. In addition, the ionic liquid cannot be changed. The crystalline structure of the cellulose in the raw material is shown 
in Fig. 9. The XRD spectra of the remaining residues in the ionic liquid at different time periods were all typical of cellulose type I. This was consistent with the findings of Kilpeläinen et al. (2007) when they treated wood with ionic liquids.

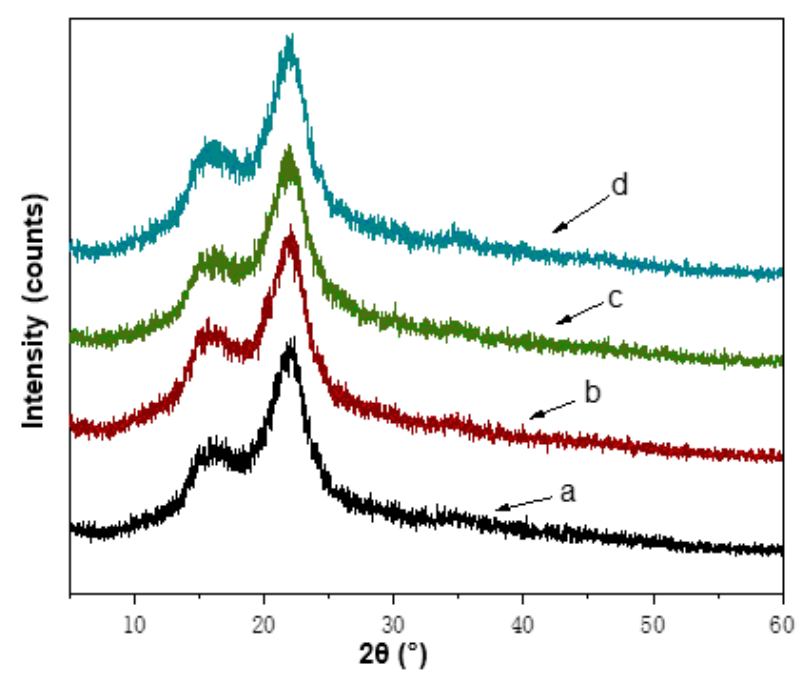

Fig. 9. The XRD of straw raw disposed at different times, which included 0 min (a), 10 min (b), 25 $\min (\mathrm{c})$, and $40 \mathrm{~min}(\mathrm{~d})$

\section{Microstructure analysis (scanning electron microscopy)}

Figure 10 shows that the straw surface was eroded by ionic liquid as the ionic liquid dissolution time increased. The straw surface became broken gradually, which indicated that the cellulose and hemicellulose and lignin in the straw were dissolved in ionic liquid. Dissolution occurred from the outside to the inside. The ionic liquid eroded the straw and left only the cellulose support skeleton, which was consistent with the solubility of cellulose.

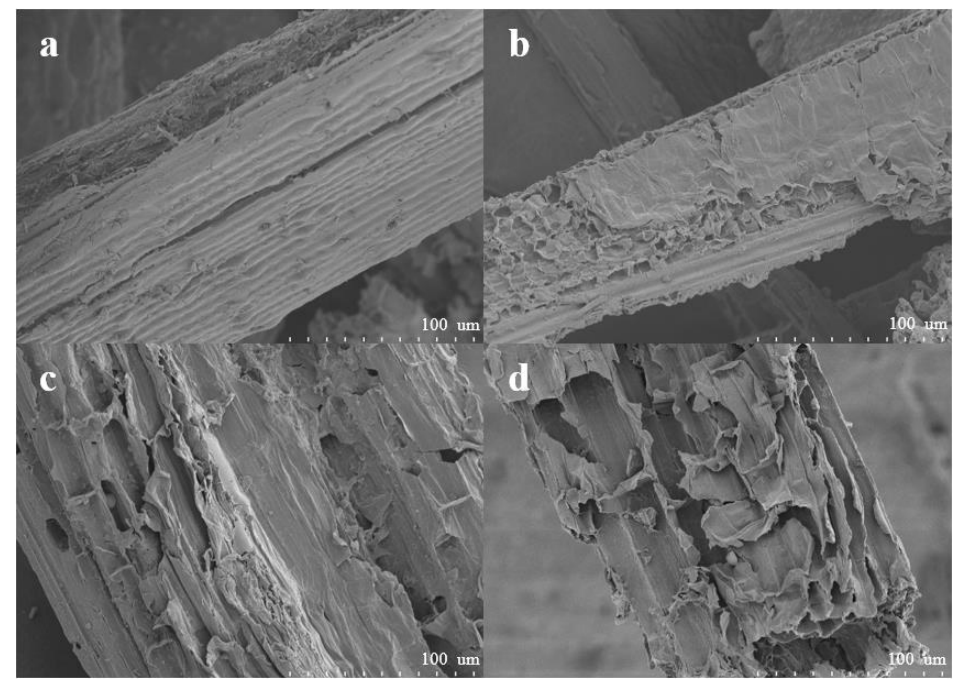

Fig. 10. A 500x enlarged image of straw raw materials treated with ionic liquid at different times, which included $0 \mathrm{~min}(\mathrm{a}), 10 \mathrm{~min}(\mathrm{~b}), 25 \mathrm{~min}(\mathrm{c})$, and $40 \mathrm{~min}(\mathrm{~d})$ 


\section{CONCLUSIONS}

1. In this experiment, rice straw was used as the raw material. The ionic liquid was used to treat the straw in a $90{ }^{\circ} \mathrm{C}$ water bath. Four sets of reaction times were set to treat the straw.

2. After shortening the period of traditional measurement methods for this experiment, the solubility of various components in different time periods was obtained by analyzing the residues of various substances in different time periods. The results showed that the dissolution rate of triglyceride fats, water-soluble pectin, and lignin peaked at $10 \mathrm{~min}$, and then the dissolution rate slowed down. Cellulose and hemicellulose were affected by the lignin in the ionic liquid, and the dissolution rate was slow.

3. Infrared spectroscopy showed that ionic liquids could dissolve cellulose, lignin, hemicellulose, wax, water-soluble substances, and pectin in straw. In addition, lignin was preferentially dissolved in the initial stage. Within wood and other plant materials, cellulose is wrapped within lignin and hemicellulose, and the breakage of hydrogen bonds between cellulose is inhibited. Therefore, lignin was dissolved in preference to cellulose.

4. This study paves the way for the utilization of straw cellulose and lignin and the industrialized use of ionic liquids to treat straw-like substances.

\section{REFERENCES CITED}

Alemdar, A., and Sain, M. (2008). "Isolation and characterization of nanofibers from agricultural residues: Wheat straw and soy hulls," Bioresource Technology 99(6), 1664-1671. DOI: 10.1016/j.biortech.2007.04.029

Athukorala, Y., and Mazza, G. (2010). "Supercritical carbon dioxide and hexane extraction of wax from triticale straw: Content, composition and thermal properties," Industrial Crops and Products 31(3), 550-556. DOI: 10.1016/j.indcrop.2010.02.011

Ayoub, A., Venditti, R. A., Pawlak, J. J., Salam, A., and Hubbe, M. A. (2013). "Novel hemicellulose-chitosan biosorbent for water desalination and heavy metal removal," ACS Sustainable Chemistry \& Engineering 1(9), 1102-1109. DOI: $10.1021 / \mathrm{sc} 300166 \mathrm{~m}$

Buchala, A. J., Fraser, C. G., and Wilkie, K. C. B. (1972). "Extraction of hemicellulose from oat tissues during the process of delignification," Phytochemistry 11(4), 12491254. DOI: 10.1016/S0031-9422(00)90071-2

Carpita, N. C. (1984). "Fractionation of hemicelluloses from maize cell walls with increasing concentrations of alkali," Phytochemistry 23(5), 1089-1093. DOI: 10.1016/S0031-9422(00)82615-1

Chen, F., Sawada, D., Hummel, M., Sixta, H., and Budtova, T. (2020a). "Swelling and dissolution kinetics of natural and man-made cellulose fibers in solvent power tuned ionic liquid," Cellulose 27(13), 7399-7415. DOI: 10.1007/s10570-020-03312-5

Chen, Z., Zhang, Q., Meng, W., Wang, Z., Han, X., and Pu, J. (2020b). "Nickel-reduced graphene oxide-cellulose nanofiber composite papers for electromagnetic interference shielding," BioResources 15(1), 814-824. DOI: 10.15376/biores.15.1.814-824 
Deng, M., Zhou, Q., Du, A., van Kasteren, J., and Wang, Y. (2009). "Preparation of nanoporous cellulose foams from cellulose-ionic liquid solutions," Materials Letters 63(21), 1851-1854. DOI: 10.1016/j.matlet.2009.05.064

Faix, O. (1991). "Classification of lignins from different botanical origins by FT-IR spectroscopy," Holzforschung 45(S1), 21-28. DOI: 10.1515/hfsg.1991.45.s1.21

Han, S., Park, C., Febrianto, F., Kim, N., and Lee, S. (2020). "Pretreatment with [EMIM]Ac/DMAc co-solvent to improve enzymatic saccharification of pussy willow (Salix gracilistyla Miq.)," BioResources 15(1), 187-198. DOI:

10.15376/biores.15.1.187-198

Hazarika, S., Dutta, N. N., and Rao, P. G. (2012). "Dissolution of lignocellulose in ionic liquids and its recovery by nanofiltration membrane," Separation and Purification Technology 97, 123-129. DOI: 10.1016/j.seppur.2012.04.026

Hubbe, M. A., and Lucia, L. A. (2015). "BioResources: Ten years of service for the progress of the science and technology of lignocellulosic products," BioResources 11(1), 1-2. DOI: 10.15376/biores.11.1.1-2

Hubbe, M. A., McLean, D. S., Stack, K. R., Lu, X. M., Strand, A., and Sundberg, A. (2020). "Self-assembly of alkyl chains of fatty acids in papermaking systems: A review of related pitch issues, hydrophobic sizing, and pH effects," BioResources 15(2), 4591-4635. DOI: 10.15376/biores.15.2.4591-4635

Hubbe, M. A., Nazhad, M. M., and Sanchez, C. (2010). "Composting as a way to convert cellulosic biomass and organic waste into high-value soil amendments: A review," BioResources 5(4), 2808-2854. DOI: 10.15376/BIORES.5.4.2808-2854

Hubbe, M. A., Park, J., and Park, S. (2014). "Cellulosic substrates for removal of pollutants from aqueous systems: A review. Part 4. Dissolved petrochemical compounds," BioResources 9(4), 7782-7925. DOI: 10.15376/biores.9.4.7782-7925

Kadokawa, J., Murakami, M. A., and Kaneko, Y. (2008). "A facile preparation of gel materials from a solution of cellulose in ionic liquid," Carbohydrate Research 343(4), 769-772. DOI: 10.1016/j.carres.2008.01.017

Kilpeläinen, I., Xie, H., King, A. W. T., Granstrom, M., Heikkinen, S., and Argyropoulos, D. S. (2007). "Dissolution of wood in ionic liquids," Journal of Agricultural and Food Chemistry 55(22), 9142-9148. DOI: 10.1021/jf071692e

Lee, S. H., Doherty, T. V., Linhardt, R. J., and Dordick, J. S. (2009). "Ionic liquidmediated selective extraction of lignin from wood leading to enhanced enzymatic cellulose hydrolysis," Biotechnology and Bioengineering 102(5), 1368-1376. DOI: 10.1002/bit.22179

Lu, B., Xu, A., and Wang, J. (2014). "Cation does matter: How cationic structure affects the dissolution of cellulose in ionic liquids," Green Chemistry 16(3), 1326-1335. DOI: $10.1039 / \mathrm{C} 3 \mathrm{GC} 41733 \mathrm{~F}$

Makela, V., Wahlstrom, R., Holopainen-Mantila, U., Kilpelainen, I., and King, A. W. T. (2018). "Clustered single cellulosic fiber dissolution kinetics and mechanisms through optical microscopy under limited dissolving conditions," Biomacromolecules 19(5), 1635-1645. DOI: 10.1021/acs.biomac.7b01797

Man, Z., Muhammad, N., Sarwono, A., Bustam, M. A., Vignesh Kumar, M., and Rafiq, S. (2011). "Preparation of cellulose nanocrystals using an ionic liquid," Journal of Polymers and the Environment 19(3), 726-731. DOI: 10.1007/s10924-011-0323-3

Miyafuji, H., Miyata, K., Saka, S., Ueda, F., and Mori, M. T. (2009). "Reaction behavior of wood in an ionic liquid, 1-ethyl-3-methylimidazolium chloride," Journal of Wood Science 55(3), 215-219. DOI: 10.1007/s10086-009-1020-x 
Pinkert, A., Marsh, K. N., Pang, S., and Staiger, M. P. (2009). "Ionic liquids and their interaction with cellulose," Chemical Reviews 109(12), 6712-6728. DOI: $10.1021 / \mathrm{cr} 9001947$

Plechkova, N. V., and Seddon, K. R. (2008). "Applications of ionic liquids in the chemical industry," Chemical Society Reviews 37(1), 123-150. DOI: 10.1039/B006677J

$\mathrm{Pu}$, Y., Jiang, N., and Ragauskas, A. J. (2007). "Ionic liquid as a green solvent for lignin," Journal of Wood Chemistry and Technology 27(1), 23-33. DOI: 10.1080/02773810701282330

Remsing, R. C., Swatloski, R. P., Rogers, R. D., and Moyna, G. (2006). "Mechanism of cellulose dissolution in the ionic liquid 1-n-butyl-3-methylimidazolium chloride: A ${ }^{13} \mathrm{C}$ and ${ }^{35 / 37} \mathrm{Cl} \mathrm{NMR}$ relaxation study on model systems," Chemical Communications 2006(12), 1271-1273. DOI: 10.1039/B600586C

Singh, S., Simmons, B. A., and Vogel, K. P. (2009). "Visualization of biomass solubilization and cellulose regeneration during ionic liquid pretreatment of switchgrass," Biotechnology and Bioengineering 104(1), 68-75. DOI: 10.1002/bit.22386

Sun, N., Rahman, M., Qin, Y., Maxim, M. L., Rodríguez, H., and Rogers, R. D. (2009). "Complete dissolution and partial delignification of wood in the ionic liquid 1-ethyl3-methylimidazolium acetate," Green Chemistry 11(5), 646-655. DOI: $10.1039 / \mathrm{B} 822702 \mathrm{~K}$

Sun, X. F., Xu, F., Sun, R. C., Fowler, P., and Baird, M. S. (2005). "Characteristics of degraded cellulose obtained from steam-exploded wheat straw," Carbohydrate Research 340(1), 97-106. DOI: 10.1016/j.carres.2004.10.022

Swatloski, R. P., Spear, S. K., Holbrey, J. D., and Rogers, R. D. (2002). "Dissolution of cellose with ionic liquids," Journal of the American Chemical Society 124(18), 49744975. DOI: 10.1021/ja025790m

Tan, S. S. Y., MacFarlane, D. R., Upfal, J., Edye, L. A., Doherty, W. O .S., Patti, A. F., Pringle, J. M., and Scott, J. L. (2009). "Extraction of lignin from lignocellulose at atmospheric pressure using alkylbenzenesulfonate ionic liquid," Green Chemistry 11(3), 339-345. DOI: 10.1039/B815310H

TAPPI T9 m-54 (1998). "Holocellulose in wood," TAPPI Press, Atlanta, GA, USA.

TAPPI T204 cm-07 (2007). "Solvent extractives of wood and pulp," TAPPI Press, Atlanta, GA, USA.

TAPPI T211 om-17 (2007). "Ash in wood, pulp, paper and paperboard: Combustion at $252{ }^{\circ} \mathrm{C}$, , TAPPI Press, Atlanta, GA, USA.

TAPPI T222 om-11 (2011). “Acid-insoluble lignin in wood and pulp," TAPPI Press, Atlanta, GA, USA.

Xiao, B., Sun, X. F., and Sun, R. (2001). "Chemical, structural, and thermal characterizations of alkali-soluble lignins and hemicelluloses, and cellulose from maize stems, rye straw, and rice straw," Polymer Degradation and Stability 74(2), 307-319. DOI: 10.1016/S0141-3910(01)00163-X

Article submitted: September 29, 2020; Peer review completed: December 5, 2020; Revised version received and accepted: December 27, 2020; Published: January 13, 2021. DOI: 10.15376/biores.16.1.1534-1547 